\title{
Dynamic Relations of Consumer Prices: A Case Study of Recent Effects on the Japanese Headline CPI
}

\author{
Chikashi Tsuji \\ Professor, Faculty of Economics, Chuo University \\ 742-1 Higashinakano Hachioji-shi, Tokyo 192-0393, Japan \\ E-mail: mail_sec_low@minos.ocn.ne.jp
}

Received: October 19, 2015 Accepted: February 6, 2016 Published: February 7, 2016

doi:10.5296/jsss.v3i2.8991 URL: http://dx.doi.org/10.5296/jsss.v3i2.8991

\begin{abstract}
This study attempts to empirically examine the relations between the headline consumer price index (CPI) and several other CPIs in Japan by applying the vector error correction models (VECMs). Our investigations derive the following interesting findings. First, we reveal that as to our four combinations of the CPIs tested in this paper, 1) all variable coefficients in the cointegrating equations are statistically significant in our VECM models and the statistical significance is very strong. Thus, we understand that our four bivariate combinations of the CPIs tested in this paper are all strongly cointegrated and the VECM approach is very effective to capture the time-series effects of the categorized CPIs on the Japanese headline CPI. Further, we also find that 2) as far as judging by the results of our impulse response analyses, for the period from May 2011 to June 2015, the headline CPI for Japan is weakly or little affected by the CPI of energy and the CPI of food for Japan. We further clarify that 3) according to the results of our impulse response analyses, the Japanese headline CPI is positively affected by both the CPI of utilities for Japan and the CPI of transportation and communication expenses for Japan.
\end{abstract}

Keywords: Cointegration, Consumer prices, Headline CPI, VECM 


\section{Introduction}

How do the energy prices or food prices affect the total index, namely, the headline consumer price index (CPI)? For example, how are the relations between prices of services or utilities and the headline CPI? In economics, consumer prices or inflation rates are significantly important and for instance, there are many existing researches of the inflation forecasting (See e.g., Stock and Watson, 1999). Currently in Japan, mainly for obtaining the suitable level of consumer prices, quantitative and qualitative easing (QQE) monetary policy is implemented by the Bank of Japan. Thus currently, the linkage among various sorts of consumer prices in Japan is one of the most interesting hot topics in business and economics.

Based on the above motivation, as a case study, this paper examines the recent effects of Japanese consumer prices of energy, food, utility, and transportation and communication expenses on the Japanese headline CPI by using the bivariate-vector error correction models (VECMs). Our examinations firstly reveal that 1) the variable coefficients in the cointegrating equations in VECMs are statistically significant in all our cases and the statistical significance is very strong. Thus, this means that our four bivariate combinations of the CPIs tested in this paper are all strongly cointegrated and the VECM approach is very effective to capture the time-series effects of the categorized CPIs on the Japanese headline CPI. Further, we also find that 2) as far as judging by the results of our impulse response analyses, the headline CPI for Japan is weakly or little affected by the CPIs of energy and food for Japan. We further clarify that 3) according to the results of our impulse response analyses, the Japanese headline CPI is positively affected by both the CPI of utilities for Japan and the CPI of transportation and communication expenses for Japan. Regarding the rest of this paper, Section 2 reviews past literature, Section 3 documents our data and variables, and Sections 4 explains our models. Section 5 then states our results and Section 6 concludes the paper.

\section{Literature Review}

This section concisely reviews past literature. Regarding CPIs, many papers studied inflation forecasting. First, Stock and Watson (1999) researched the predictability of the US inflation. They showed that the forecasts from the Phillips curve could be improved by using a generalized Phillips curve based on their novel aggregate activity index. Using the data from 1980 to 2001, Gerlach and Svensson (2003) studied the indicators of inflation for the euro area by analyzing some economic variable relations. Their main finding was that both the output gap and the real money gap contain much information as to future inflation. Further, Ang et al. (2007) empirically tested the out-of-sample predictive power of several alternative US inflation forecasting methods and showed that surveys forecast better than the other forecasting methods.

Manzan and Zerom (2013) found that some macro indicators, such as housing starts, unemployment rates, and the term spreads, showed significant out-of-sample forecasting power for the distribution of the US core inflation. Further, using monthly data of Ethiopia over 10 years, Durevall et al. (2013) estimated models of inflation to clarify the important factors contributing to CPI inflation and its major components of food prices, non-food prices, 
and cereal prices. Furthermore, using the testing method suggested by Homm and Breitung (2012) and the US data from 1982 to 2010, Arora et al. (2013) identified the periods when the headline price index in terms of personal consumption expenditures (PCEs) largely fluctuates relative to the core PCE.

Table 1. Descriptive statistics of CPIs in Japan

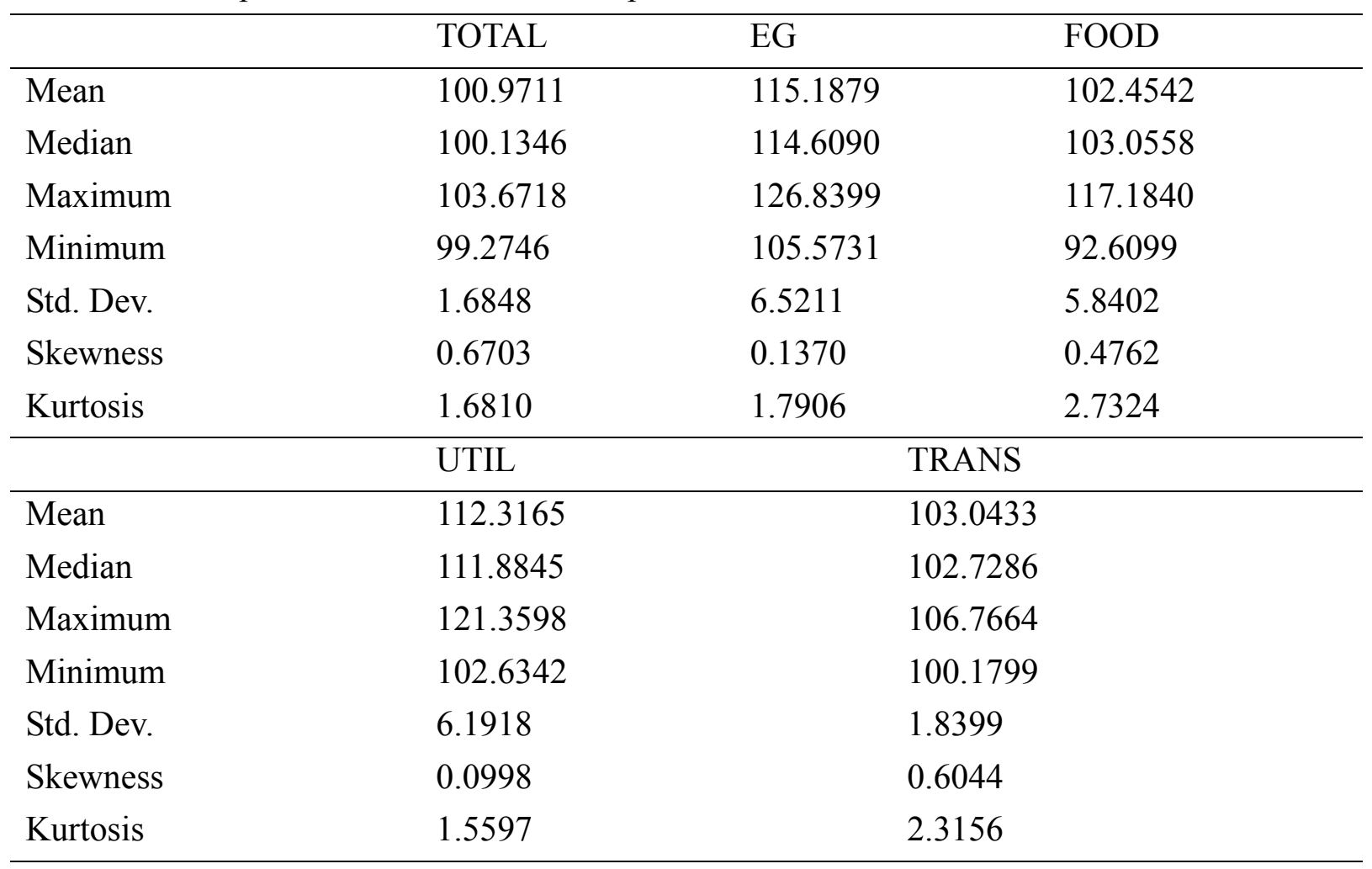

Notes: This table displays the descriptive statistics as to the variables examined in this study. In this table, 'Std. Dev.' denotes the value of standard deviation. As regards the variables, TOTAL means the total CPI of all items for Japan; EG denotes the CPI of energy for Japan; FOOD represents the CPI of food for Japan; UTIL denotes the CPI of utilities for Japan; and TRANS means the CPI of transportation and communication expenses for Japan. Our samples are monthly and the sample period is from May 2011 to June 2015.

\section{Data}

In this section, we explain the data investigated in this study. This research uses five sorts of Japanese consumer price indices. Documenting our variables more specifically, TOTAL means the total CPI of all items (the headline CPI) for Japan; EG denotes the CPI of energy for Japan; and FOOD represents the CPI of food for Japan. Further, UTIL denotes the CPI of utilities for Japan and TRANS means the CPI of transportation and communication expenses for Japan. All the variables explained above are seasonally adjusted; our samples are monthly time-series and the sample period for our empirical analyses spans May 2011 to June 2015. All data investigated in this research are from the QUICK Corp.

The time-series trends as to the above five kinds of Japanese CPIs are displayed in Figure 1. 


\section{Macrothink}

In addition, their descriptive statistics are shown in Table 1. From Figure 1, we understand that the CPI of energy (EG) and the CPI of utilities (UTIL) largely and continuously increased until they began to decrease around the middle of 2014. On the other hand, the CPI of transportation and communication expenses (TRANS) only gradually increased in our sample period and the total CPI of all items (TOTAL) also very gradually increased only in the recent years. In addition, we also understand that from Figure 1, the time-series of the CPI of food (FOOD) was very volatile throughout our sample period.

Further, Table 1 suggests the following data characteristics of our five Japanese CPIs. First, Table 1 shows that the standard deviation values of TOTAL and TRANS are lower. Table 1 also indicates that the values of standard deviation are higher for the variables, EG, FOOD, and UTIL. The higher standard deviation values of EG and UTIL may be because of their larger increasing trends generally seen in Figure 1.

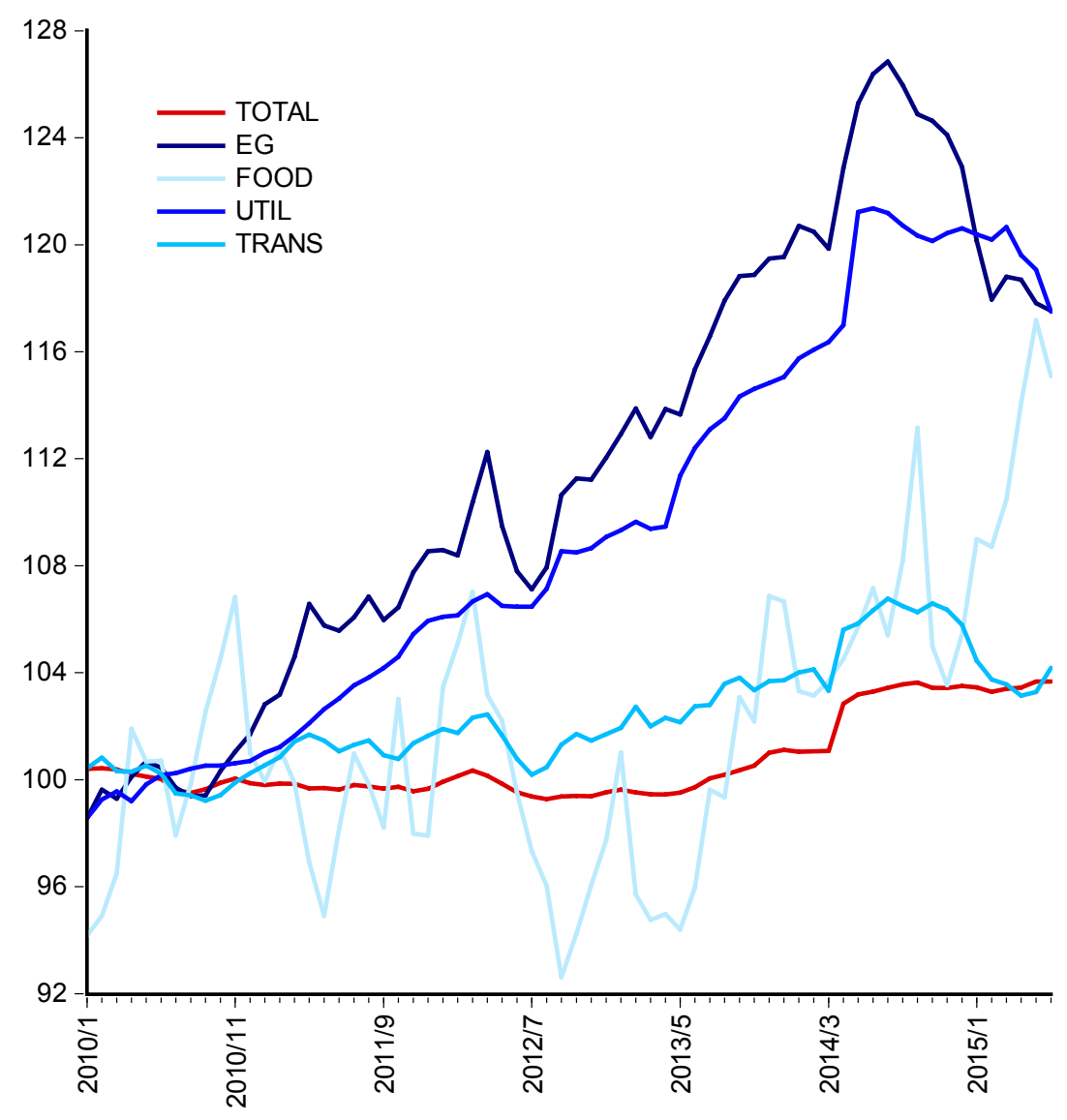

Figure 1. Time-series of CPIs in Japan: Evolution from January 2010 to June 2015.

\section{Models}

This section explains our models for empirical examinations. For testing the effects of four kinds of CPIs, EG, FOOD, UTIL, and TRANS on the total Japanese CPI, TOTAL, we examine four kinds of VECMs. Namely, we investigate the bivariate-VECMs of 1) TOTAL and EG; 2) TOTAL and FOOD; 3) TOTAL and UTIL; and 4) TOTAL and TRANS. Our model determinations are according to the Johansen's (1991; 1995) cointegration tests and all 
our models can be summarized as the following equations (1) and (2):

$$
\begin{aligned}
& \Delta m_{t}=\tau_{1} C E+\sum_{w=1}^{p} \xi_{1, w} \Delta m_{t-w}+\sum_{j=1}^{q} \phi_{1, j} \Delta h_{t-j}+\kappa_{1, t}, \\
& \Delta h_{t}=\tau_{2} C E+\sum_{r=1}^{p} \xi_{2, r} \Delta m_{t-r}+\sum_{s=1}^{q} \phi_{2, s} \Delta h_{t-s}+\kappa_{2, t} .
\end{aligned}
$$

In the above models, $m$ means the variable TOTAL and $h$ means one of other CPIs. Moreover, $\Delta m$ and $\Delta h$ represent the first differences as to the variables $m$ and $h$, respectively.

In addition, the VECM of TOTAL and FOOD, cointegrating equations (CEs) in the above equations include an intercept as $C E=m_{t-1}+\lambda h_{t-1}+\eta$ whilst other three VECMs include no intercept as $C E=m_{t-1}+\lambda h_{t-1}$. Further, $p$ and $q$ in equations (1) and (2) are the model lag orders. As a result, our determined four models for the Japanese CPIs are 1) $\operatorname{VECM}(2)$ for TOTAL and EG; 2) VECM(10) for TOTAL and FOOD; 3) VECM(8) for TOTAL and UTIL; and 4) $\operatorname{VECM(6)~for~TOTAL~and~TRANS.~}$

Table 2. Estimation results of the VECMs for CPIs: The cases of the CPIs of total, energy,

\begin{tabular}{|c|c|c|c|c|c|}
\hline \multicolumn{3}{|c|}{ Panel A. TOTAL and EG } & \multicolumn{3}{|c|}{ Panel B. TOTAL and FOOD } \\
\hline \multicolumn{3}{|c|}{ Cointegrating equation } & \multicolumn{3}{|c|}{ Cointegrating equation } \\
\hline & \multicolumn{2}{|l|}{ Coefficients } & & \multicolumn{2}{|l|}{ Coefficients } \\
\hline TOTAL $(-1)$ & \multicolumn{2}{|l|}{1.0000} & TOTAL $(-1)$ & \multicolumn{2}{|l|}{1.0000} \\
\hline $\mathrm{EG}(-1)$ & \multicolumn{2}{|l|}{$-0.8865 * * *$} & $\operatorname{FOOD}(-1)$ & \multicolumn{2}{|l|}{$-0.3039 * * *$} \\
\hline$t$-value & \multicolumn{2}{|l|}{-89.0334} & $t$-value & \multicolumn{2}{|l|}{-8.3960} \\
\hline \multirow[t]{4}{*}{$p$-value } & \multirow{4}{*}{\multicolumn{2}{|c|}{0.0000}} & $p$-value & \multicolumn{2}{|l|}{0.0000} \\
\hline & & & Intercept & \multicolumn{2}{|l|}{$-69.7357 * * *$} \\
\hline & & & $t$-value & \multicolumn{2}{|l|}{-19.2814} \\
\hline & & & $p$-value & \multicolumn{2}{|l|}{0.0000} \\
\hline \multicolumn{3}{|c|}{ Error corrections } & \multicolumn{3}{|c|}{ Error corrections } \\
\hline & \multicolumn{2}{|l|}{ Variables } & & \multicolumn{2}{|l|}{ Variables } \\
\hline & $\triangle \mathrm{TOTAL}$ & $\Delta \mathrm{EG}$ & & $\triangle \mathrm{TOTAL}$ & $\triangle \mathrm{FOOD}$ \\
\hline & Coefficients & Coefficients & & Coefficients & Coefficients \\
\hline $\mathrm{CE}$ & -0.0174 & $0.0776^{*}$ & $\mathrm{CE}$ & 0.1125 & $3.2964 * * *$ \\
\hline$t$-value & -1.5457 & 1.7825 & $t$-value & 0.5870 & 3.5615 \\
\hline$p$-value & 0.1292 & 0.0814 & $p$-value & 0.5618 & 0.0013 \\
\hline$\triangle \mathrm{TOTAL}(-1)$ & 0.2137 & $1.4646^{* *}$ & $\triangle \mathrm{TOTAL}(-1)$ & 0.0901 & -1.0933 \\
\hline$t$-value & 1.1958 & 2.1204 & $t$-value & 0.3049 & -0.7662 \\
\hline$p$-value & 0.2380 & 0.0395 & $p$-value & 0.7627 & 0.4498 \\
\hline$\triangle$ TOTAL $(-2)$ & -0.0960 & 0.7687 & $\triangle \mathrm{TOTAL}(-2)$ & -0.1306 & -0.8988 \\
\hline$t$-value & -0.5041 & 1.0446 & $t$-value & -0.5015 & -0.7143 \\
\hline
\end{tabular}
food, utilities, and transportation and communication expenses for Japan 


\begin{tabular}{|c|c|c|c|c|c|}
\hline$p$-value & 0.6166 & 0.3018 & $p$-value & 0.6198 & 0.4807 \\
\hline$\Delta \mathrm{EG}(-1)$ & 0.0026 & 0.2284 & $\triangle \mathrm{TOTAL}(-3)$ & -0.0930 & $-4.2115 * * *$ \\
\hline$t$-value & 0.0582 & 1.3480 & $t$-value & -0.3558 & -3.3365 \\
\hline$p$-value & 0.9539 & 0.1844 & $p$-value & 0.7246 & 0.0023 \\
\hline$\Delta \mathrm{EG}(-2)$ & 0.0115 & -0.1806 & $\triangle \mathrm{TOTAL}(-4)$ & 0.1283 & -0.3007 \\
\hline$t$-value & 0.2764 & -1.1273 & $t$-value & 0.4391 & -0.2131 \\
\hline \multirow[t]{31}{*}{$p$-value } & 0.7835 & 0.2656 & $p$-value & 0.6639 & 0.8327 \\
\hline & & & $\triangle \mathrm{TOTAL}(-5)$ & 0.2033 & 0.6481 \\
\hline & & & $t$-value & 0.6867 & 0.4531 \\
\hline & & & $p$-value & 0.4977 & 0.6539 \\
\hline & & & $\triangle \mathrm{TOTAL}(-6)$ & -0.2594 & $-5.6698 * * *$ \\
\hline & & & $t$-value & -0.9275 & -4.1968 \\
\hline & & & $p$-value & 0.3613 & 0.0002 \\
\hline & & & $\triangle \mathrm{TOTAL}(-7)$ & -0.0161 & -2.9992 \\
\hline & & & $t$-value & -0.0428 & -1.6473 \\
\hline & & & $p$-value & 0.9662 & 0.1103 \\
\hline & & & $\triangle \mathrm{TOTAL}(-8)$ & 0.1439 & -2.1768 \\
\hline & & & $t$-value & 0.3548 & -1.1109 \\
\hline & & & $p$-value & 0.7253 & 0.2758 \\
\hline & & & $\triangle \mathrm{TOTAL}(-9)$ & -0.2792 & -0.0966 \\
\hline & & & $t$-value & -0.8392 & -0.0601 \\
\hline & & & $p$-value & 0.4082 & 0.9525 \\
\hline & & & $\triangle \mathrm{TOTAL}(-10)$ & -0.3407 & -0.7142 \\
\hline & & & $t$-value & -1.0817 & -0.4695 \\
\hline & & & $p$-value & 0.2883 & 0.6423 \\
\hline & & & $\Delta \mathrm{FOOD}(-1)$ & 0.0511 & $0.4679 *$ \\
\hline & & & $t$-value & 0.9748 & 1.8462 \\
\hline & & & $p$-value & 0.3377 & 0.0751 \\
\hline & & & $\Delta \mathrm{FOOD}(-2)$ & 0.0520 & $0.5671 * *$ \\
\hline & & & $t$-value & 1.1879 & 2.6808 \\
\hline & & & $p$-value & 0.2445 & 0.0120 \\
\hline & & & $\Delta \mathrm{FOOD}(-3)$ & -0.0115 & $0.5804 * *$ \\
\hline & & & $t$-value & -0.2490 & 2.6060 \\
\hline & & & $p$-value & 0.8051 & 0.0143 \\
\hline & & & $\Delta \mathrm{FOOD}(-4)$ & -0.0034 & $0.4906 * *$ \\
\hline & & & $t$-value & -0.0691 & 2.0793 \\
\hline & & & $p$-value & 0.9454 & 0.0465 \\
\hline
\end{tabular}




\begin{tabular}{|c|c|c|c|c|c|}
\hline & & & $\Delta \mathrm{FOOD}(-5)$ & 0.0381 & $0.4315 * *$ \\
\hline & & & $t$-value & 0.9241 & 2.1676 \\
\hline & & & $p$-value & 0.3631 & 0.0385 \\
\hline & & & $\Delta \mathrm{FOOD}(-6)$ & 0.0186 & $0.4149 * *$ \\
\hline & & & $t$-value & 0.4650 & 2.1432 \\
\hline & & & $p$-value & 0.6454 & 0.0406 \\
\hline & & & $\Delta \mathrm{FOOD}(-7)$ & 0.0383 & $0.3127 *$ \\
\hline & & & $t$-value & 1.0385 & 1.7538 \\
\hline & & & $p$-value & 0.3076 & 0.0900 \\
\hline & & & $\Delta \mathrm{FOOD}(-8)$ & 0.0329 & $0.4620 * *$ \\
\hline & & & $t$-value & 0.8855 & 2.5743 \\
\hline & & & $p$-value & 0.3832 & 0.0154 \\
\hline & & & $\Delta \mathrm{FOOD}(-9)$ & 0.0468 & 0.1689 \\
\hline & & & $t$-value & 1.2347 & 0.9220 \\
\hline & & & $p$-value & 0.2268 & 0.3641 \\
\hline & & & $\Delta \mathrm{FOOD}(-10)$ & 0.0202 & $0.3442 *$ \\
\hline & & & $t$-value & 0.5412 & 1.9053 \\
\hline & & & $p$-value & 0.5925 & 0.0667 \\
\hline $\mathrm{AIC}$ & 0.5372 & 3.2410 & $\mathrm{AIC}$ & 1.2771 & 4.4270 \\
\hline $\mathrm{SC}$ & 0.7340 & 3.4378 & $\mathrm{SC}$ & 2.1729 & 5.3228 \\
\hline
\end{tabular}

Panel C. TOTAL and UTIL

Panel D. TOTAL and TRANS

\begin{tabular}{llll}
\hline \multicolumn{2}{l}{ Cointegrating equation } & \multicolumn{2}{l}{ Cointegrating equation } \\
\hline & Coefficients & & Coefficients \\
\hline TOTAL $(-1)$ & 1.0000 & TOTAL $(-1)$ & 1.0000 \\
UTIL $(-1)$ & $-0.8980 * * *$ & TRANS $(-1)$ & $-0.9820 * * *$ \\
$t$-value & -62.7605 & $t$-value & -677.4080 \\
$p$-value & 0.0000 & $p$-value & 0.0000
\end{tabular}

Error corrections Error corrections

\begin{tabular}{llllll}
\hline & Variables & & \multicolumn{3}{l}{ Variables } \\
\hline & $\Delta$ TOTAL & $\Delta$ UTIL & & $\Delta$ TOTAL & $\Delta$ TRANS \\
\hline CE & Coefficients & Coefficients & & Coefficients & Coefficients \\
$t$-value & -0.0310 & $0.1012^{* *}$ & CE & $-0.2110^{* *}$ & 0.0735 \\
$p$-value & -1.3395 & 2.1421 & $t$-value & -2.0864 & 0.3445 \\
$\Delta$ TOTAL $(-1)$ & 0.1896 & 0.0397 & $p$-value & 0.0439 & 0.7324 \\
$t$-value & 0.6698 & 3.9569 & $t$-value & 2.3198 & 0.7921 \\
$p$-value & 0.5076 & 0.0004 & $p$-value & 0.0260 & 0.4334
\end{tabular}




\begin{tabular}{|c|c|c|c|c|c|}
\hline$\triangle \mathrm{TOTAL}(-2)$ & -0.2175 & -0.7751 & $\triangle \mathrm{TOTAL}(-2)$ & -0.0621 & -0.1647 \\
\hline$t$-value & -0.8278 & -1.4473 & $t$-value & -0.2539 & -0.3191 \\
\hline$p$-value & 0.4137 & 0.1573 & $p$-value & 0.8010 & 0.7515 \\
\hline$\triangle \mathrm{TOTAL}(-3)$ & -0.3720 & -0.2307 & $\triangle \mathrm{TOTAL}(-3)$ & 0.0131 & 0.4853 \\
\hline$t$-value & -1.3926 & -0.4238 & $t$-value & 0.0567 & 0.9981 \\
\hline$p$-value & 0.1730 & 0.6745 & $p$-value & 0.9551 & 0.3247 \\
\hline$\triangle \mathrm{TOTAL}(-4)$ & -0.2805 & -0.0533 & $\triangle \mathrm{TOTAL}(-4)$ & 0.1886 & -0.5948 \\
\hline$t$-value & -0.9999 & -0.0931 & $t$-value & 0.8444 & -1.2614 \\
\hline$p$-value & 0.3247 & 0.9264 & $p$-value & 0.4039 & 0.2151 \\
\hline$\triangle \mathrm{TOTAL}(-5)$ & 0.3512 & -0.2099 & $\triangle \mathrm{TOTAL}(-5)$ & -0.0117 & -0.1304 \\
\hline$t$-value & 1.1260 & -0.3301 & $t$-value & -0.0480 & -0.2532 \\
\hline$p$-value & 0.2683 & 0.7434 & $p$-value & 0.9619 & 0.8015 \\
\hline$\triangle \mathrm{TOTAL}(-6)$ & -0.1503 & 0.8666 & $\triangle \mathrm{TOTAL}(-6)$ & 0.2286 & 0.8298 \\
\hline$t$-value & -0.4752 & 1.3444 & $t$-value & 0.9027 & 1.5516 \\
\hline$p$-value & 0.6378 & 0.1880 & $p$-value & 0.3725 & 0.1293 \\
\hline$\triangle \mathrm{TOTAL}(-7)$ & 0.0181 & 0.3911 & $\Delta \mathrm{TRANS}(-1)$ & $-0.2622 * *$ & 0.0247 \\
\hline$t$-value & 0.0578 & 0.6118 & $t$-value & -2.0366 & 0.0910 \\
\hline$p$-value & 0.9543 & 0.5449 & $p$-value & 0.0489 & 0.9280 \\
\hline$\triangle \mathrm{TOTAL}(-8)$ & -0.0454 & 0.9337 & $\Delta \mathrm{TRANS}(-2)$ & -0.0486 & 0.2979 \\
\hline$t$-value & -0.1456 & 1.4686 & $t$-value & -0.3507 & 1.0186 \\
\hline$p$-value & 0.8851 & 0.1514 & $p$-value & 0.7278 & 0.3150 \\
\hline$\Delta \mathrm{UTIL}(-1)$ & 0.0615 & 0.2510 & $\Delta \mathrm{TRANS}(-3)$ & -0.1008 & -0.1490 \\
\hline$t$-value & 0.6132 & 1.2274 & $t$-value & -0.7894 & -0.5527 \\
\hline$p$-value & 0.5440 & 0.2284 & $p$-value & 0.4349 & 0.5838 \\
\hline$\Delta \mathrm{UTIL}(-2)$ & 0.1233 & 0.1177 & $\Delta \mathrm{TRANS}(-4)$ & $-0.2359 * *$ & 0.0983 \\
\hline$t$-value & 1.2174 & 0.5702 & $t$-value & -2.0747 & 0.4094 \\
\hline$p$-value & 0.2321 & 0.5724 & $p$-value & 0.0450 & 0.6846 \\
\hline$\Delta \mathrm{UTIL}(-3)$ & 0.1629 & 0.0611 & $\Delta \mathrm{TRANS}(-5)$ & -0.0676 & 0.0470 \\
\hline$t$-value & 1.5163 & 0.2793 & $t$-value & -0.5261 & 0.1734 \\
\hline$p$-value & 0.1390 & 0.7818 & $p$-value & 0.6020 & 0.8633 \\
\hline$\Delta \mathrm{UTIL}(-4)$ & -0.0529 & 0.2604 & $\Delta \mathrm{TRANS}(-6)$ & $-0.2977 * *$ & -0.4596 \\
\hline$t$-value & -0.4551 & 1.0997 & $t$-value & -2.1333 & -1.5598 \\
\hline$p$-value & 0.6520 & 0.2794 & $p$-value & 0.0396 & 0.1273 \\
\hline$\Delta \mathrm{UTIL}(-5)$ & 0.0327 & -0.1252 & & & \\
\hline$t$-value & 0.2783 & -0.5232 & & & \\
\hline$p$-value & 0.7825 & 0.6044 & & & \\
\hline$\Delta \mathrm{UTIL}(-6)$ & 0.0273 & 0.1017 & & & \\
\hline
\end{tabular}




\begin{tabular}{llllll}
\hline$t$-value & 0.2343 & 0.4284 & & \\
$p$-value & 0.8162 & 0.6711 & & \\
$\Delta$ UTIL(-7) & 0.0276 & -0.3202 & & \\
$t$-value & 0.2512 & -1.4321 & & \\
$p$-value & 0.8032 & 0.1615 & & & \\
$\Delta$ UTIL(-8) & -0.0585 & 0.1169 & & & \\
$t$-value & -0.8007 & 0.7852 & & 0.7166 & 2.2113 \\
$p$-value & 0.4290 & 0.4380 & & 1.2491 & 2.7437 \\
\hline AIC & 0.9651 & 2.3892 & AIC & SC & \\
SC & 1.6756 & 3.0997 & & & \\
\hline
\end{tabular}

Notes: This table shows the estimation results of the bivariate-VECMs for five Japanese CPIs. TOTAL means the total CPI of all items for Japan; EG is the CPI of energy for Japan; FOOD means the CPI of food for Japan; UTIL is the CPI of utilities for Japan; and TRANS denotes the CPI of transportation and communication expenses for Japan. Our monthly sample period is from May 2011 to June 2015. In addition, CE denotes the cointegrating equation; AIC is the Akaike's information criterion; and SC means the Schwartz information criterion. Moreover, $* * *, * *$, and $*$ mean the statistical significance at the 1,5 , and $10 \%$ levels, respectively.

\section{Empirical Results}

This section explains our empirical results. First, Table 2 shows the estimation results of our four kinds of VECMs documented above. More concretely, in Table 2, Panel A displays the estimation results of TOTAL and EG, Panel B shows the results of TOTAL and FOOD, Panel $\mathrm{C}$ exhibits those of TOTAL and UTIL, and Panel D presents those of TOTAL and TRANS. From Table 2, it is understood that, in the CEs, all the coefficients $\lambda s$ are statistically significant with negative signs in all our four models and the statistical significance is very strong in all our four cases. Thus, we understand that our four time-series combinations of the CPIs tested in this study are all strongly cointegrated. Hence, our estimation results suggest that the VECM approach is very effective to capture the time-series relationships of the four bivariate combinations as to Japanese CPIs examined in this study.

Next, in order to empirically examine the effects of the CPIs of energy, food, utilities, and transportation and communication expenses for Japan on the total CPI of all items for Japan, we derive the impulse response functions of the Japanese total CPI and depict them in Figure 2. In this figure, Panel A exhibits the impulse response of TOTAL to EG, Panel B presents the response of TOTAL to FOOD, Panel $\mathrm{C}$ exhibits that of TOTAL to UTIL, and Panel D presents that of TOTAL to TRANS. From Figure 2, it is understood that 1) as far as judging by the results of our impulse response analyses, the total CPI for Japan is affected by the CPI of energy for Japan very weakly (Panel A) and the CPI of food for Japan has little effect on the total Japanese CPI (Panel B). Further, Figure 2 also suggests that 2) according to the results of our impulse response analyses, the total CPI for Japan is positively affected by both the Japanese CPI of utilities (Panel C) and the Japanese CPI of transportation and communication expenses (Panel D). 
Panel A. Response of TOTAL to EG

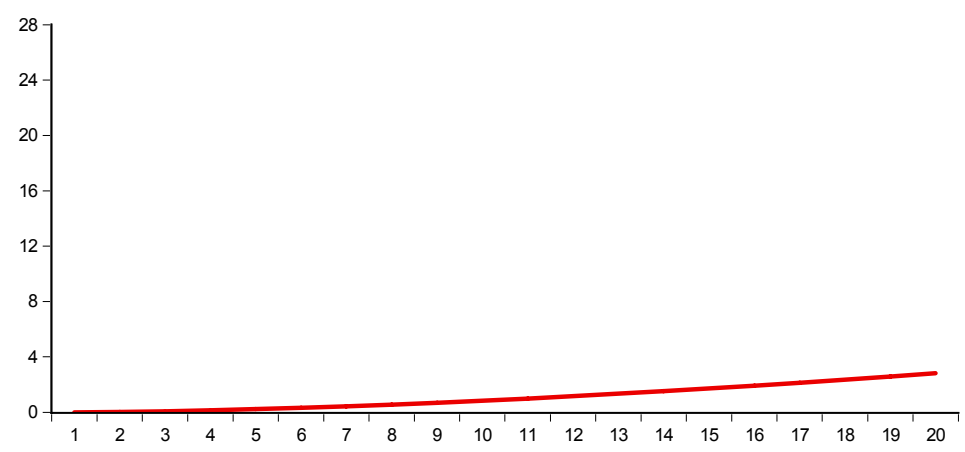

Panel B. Response of TOTAL to FOOD

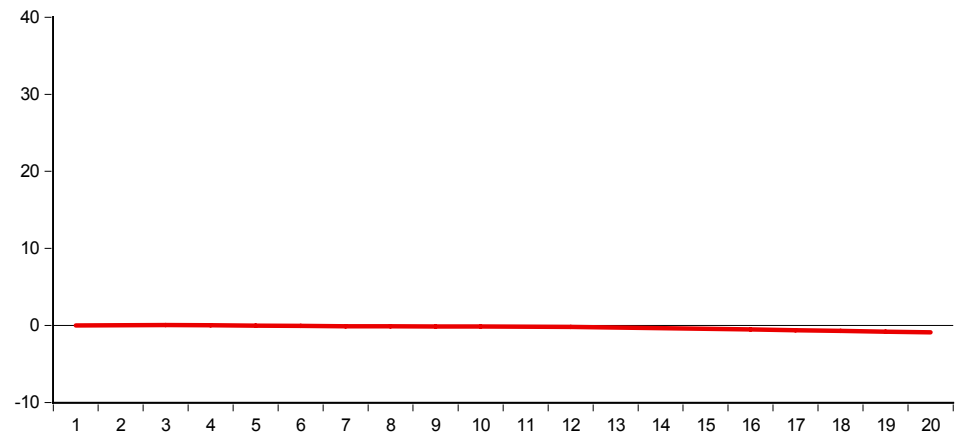

Panel C. Response of TOTAL to UTIL

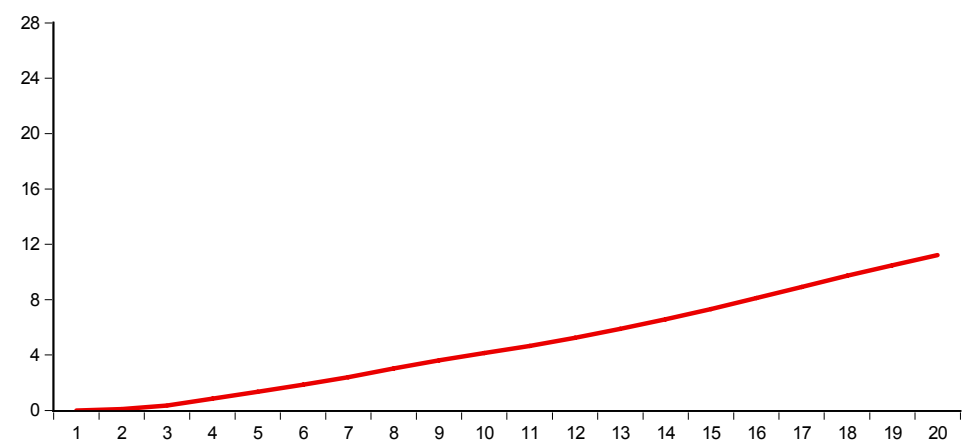

Panel D. Response of TOTAL to TRANS

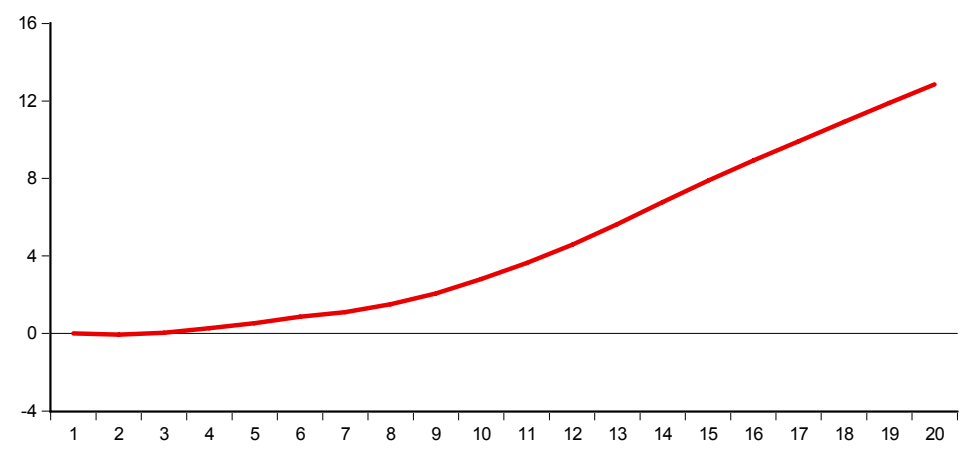

Figure 2. Impulse Responses of the Total CPI to Other CPIs in Japan. 


\section{Implications and Conclusions}

This study attempted to empirically examine the relations of several CPIs in Japan by applying the VECMs. Our investigations derived the following interesting findings. First, we revealed that 1) all variable coefficients in the cointegrating equations were statistically significant in all our VECM models; and the statistical significance was very strong. Thus, our four bivariate combinations of the CPIs tested in this paper were all strongly cointegrated; our results therefore suggested that the VECM approach was very effective to capture the time-series effects of our categorized CPIs examined in this study on the Japanese headline CPI.

Further, we also found that 2) as far as judging by the results of our impulse response analyses, for the period from May 2011 to June 2015, the headline CPI for Japan was weakly or little affected by the CPIs of energy and food for Japan. Furthermore, we also found that 3 ) according to the results of our impulse response analyses, the Japanese headline CPI was positively affected by both the CPI of utilities for Japan and the CPI of transportation and communication expenses for Japan.

In fact, the trends of CPIs are currently paid much attention to in Japan because of the prolonged Japan's deflation. To pull the Japanese economy out of deflation by meeting its 2-percent inflation target, which are suggested by the Bank of Japan, the Japanese government and central bankers should increase the Japanese consumer prices a little more. As our results indicate, the consumer prices that largely affect the headline or core CPI for Japan are important. To grasp the state and linkage of consumer prices in Japan more effectively and exactly, it is also important to carefully watch the Japanese categorized consumer prices in more detail.

Recently, Hammoudeh et al. (2015) analyzed US monetary policy and sectoral commodity prices and Pourroy et al. (2016) investigated the food prices and inflation targeting in emerging economies, for example; however, unlike our present study, little studies have investigated the consumer prices in deflation economy or very low interest rate economies. Hence, we consider that the findings and implications derived from our applications of VECMs in this study are informative for the future research which further improves our understanding on real economy. Thus, further extended and detailed research of consumer price evolution and effects in Japan shall be one of our future tasks.

\section{Acknowledgement}

I am particularly grateful to the repeated kind invitation from the journal to write to this journal. I also appreciate the Japan Society for the Promotion of Science for their generous financial assistance to this research. Moreover, I thank the anonymous referees of this journal for their comments on this paper. Furthermore, I particularly thank the Editor, John Smith, for his kindness to my paper and I also deeply thank all Editors of this journal.

\section{References}

Ang, A., Bekaert, G., \& Wei, M. (2007). Do macro variables, asset markets, or surveys 
forecast inflation better? Journal of Monetary Economics, 54, 1163-212. doi:10.1016/j.jmoneco.2006.04.006

Arora, V., Gomis-Porqueras, P., \& Shi, S. (2013). The divergence between core and headline inflation: Implications for consumers' inflation expectations. Journal of Macroeconomics, 38, 497-504. http://dx.doi.org/10.1016/j.jmacro.2013.07.006

Durevall, D., Loening, J, L., \& Birru, Y, A. (2013). Inflation dynamics and food prices in Ethiopia. Journal of Development Economics, 104, 89-106. http://dx.doi.org/10.1016/j.jdeveco.2013.05.002

Gerlach, S., \& Svensson, L. E. O. (2003). Money and inflation in the euro area: A case for monetary indicators? Journal of Monetary Economics, 50, 1649-1672. http://dx.doi.org/10.1016/j.jmoneco.2003.02.002

Hammoudeh, S., Nguyen, D. K., \& Sousa, R M. (2015). US monetary policy and sectoral commodity prices. Journal of International Money and Finance, 57, 61-85. http://dx.doi.org/10.1016/j.jimonfin.2015.06.003

Homm, U., \& Breitung, J. (2012). Testing for speculative bubbles in stock markets: A comparison of alternative methods. Journal of Financial Econometrics, 10, 198-231. http://dx.doi.org/10.1093/jjfinec/nbr009

Johansen, S. (1991). Estimation and hypothesis testing of cointegration vectors in gaussian vector autoregressive models. Econometrica, 59, 1551-1580. http://dx.doi.org/ $10.2307 / 2938278$

Johansen, S. (1995). Likelihood-based Inference in cointegrated vector autoregressive models. Oxford: Oxford University Press.

Manzan, S., \& Zerom, D. (2013). Are macroeconomic variables useful for forecasting the distribution of U.S. inflation? International Journal of Forecasting, 29, 469-478. http://dx.doi.org/10.1016/j.ijforecast.2013.01.005

Pourroy, M., Carton, B., \& Coulibaly, D. (2016). Food prices and inflation targeting in emerging economies. International forthcoming. http://dx.doi.org/10.1016/j.inteco.2015.12.001

Stock, J. H., \& Watson, M, W. (1999). Forecasting inflation. Journal of Monetary Economics, 44, 293-335. http://dx.doi.org/ 10.1016/S0304-3932(99)00027-6

\section{Copyright Disclaimer}

Copyright for this article is retained by the author(s), with first publication rights granted to the journal.

This is an open-access article distributed under the terms and conditions of the Creative Commons Attribution license (http://creativecommons.org/licenses/by/3.0/). 